\title{
Black hawk down?: Establishing helicopter parenting as a distinct construct from other forms of parental control during emerging adulthood
}

\author{
Laura M. Padilla-Walker \\ Brigham Young University - Provo \\ Larry J. Nelson \\ Brigham Young University - Provo, larry_nelson@byu.edu
}

Follow this and additional works at: https://scholarsarchive.byu.edu/facpub

Part of the Other Social and Behavioral Sciences Commons

\section{Original Publication Citation}

Padilla-Walker, L. M., \& Nelson, L. J. (2012). Black hawk down? Establishing helicopter parenting as a distinct construct from other forms of parental control during emerging adulthood. Journal of Adolescence, 35, 1177-1190.

\section{BYU ScholarsArchive Citation}

Padilla-Walker, Laura M. and Nelson, Larry J., "Black hawk down?: Establishing helicopter parenting as a distinct construct from other forms of parental control during emerging adulthood" (2012). Faculty Publications. 4687.

https://scholarsarchive.byu.edu/facpub/4687

This Peer-Reviewed Article is brought to you for free and open access by BYU ScholarsArchive. It has been accepted for inclusion in Faculty Publications by an authorized administrator of BYU ScholarsArchive. For more information, please contact ellen_amatangelo@byu.edu. 


\title{
Black hawk down?: Establishing helicopter parenting as a distinct construct from other forms of parental control during emerging adulthood
}

\author{
Laura M. Padilla-Walker*, Larry J. Nelson \\ School of Family Life, Brigham Young University, Provo, UT 84602, USA
}

Keywords:

Helicopter parenting

Parental control

Oversolicitous parenting

Parental involvement

Emerging adulthood

\begin{abstract}
A B S T R A C T
The purpose of the current study was to establish a measure of helicopter parenting that was distinct from other forms of parental control, and to examine parental and behavioral correlates of helicopter parenting. Participants included 438 undergraduate students from four universities in the United States $\left(M_{\mathrm{age}}=19.65, \mathrm{SD}=2.00\right.$, range $=18-29 ; 320$ women, 118 men), and at least one of their parents. Analyses revealed that helicopter parenting loaded on a separate factor from both behavioral and psychological control, and that helicopter parenting was positively associated with behavioral and psychological control, but not at levels suggesting complete overlap. Results also revealed that helicopter parenting was positively associated with parental involvement and with other positive aspects of the parent-child relationship; but negatively associated with parental autonomy granting and school engagement. Discussion focuses on the implications of helicopter parenting for healthy development during emerging adulthood.

(c) 2012 The Foundation for Professionals in Services for Adolescents. Published by Elsevier Ltd. All rights reserved.
\end{abstract}

Because substantial societal changes have occurred in the past few decades, the onset of adulthood is delayed in westernized nations (Arnett, 2000), subsequently extending parental involvement (Nelson et al., 2007). While it is tempting to extrapolate data from the parent-adolescent dynamic to emerging adults, the nature of emerging adults' living situation (i.e., many emerging adults no longer reside with their parents) and their growing need for independence and self-reliance, fundamentally change the nature of parenting (Nelson, Padilla-Walker, Christensen, Evans, \& Carroll, 2011). Popular culture has used the term helicopter parenting (or parenting involving hovering parents who are potentially over-involved in the lives of their child) to describe the behavior of some parents of emerging adults (e.g., Gabriel, 2010; Marano, 2010), but empirical research has not adequately defined or distinguished this construct from other controlling parenting practices. Thus, the purpose of the current study was to examine the relations between helicopter parenting and other forms of parental control (namely behavioral and psychological control) during emerging adulthood to determine if helicopter parenting is a distinct form of parental control.

\section{Parental control}

Schaefer (1965a,b) identified three important aspects, or dimensions, of parenting: (1) acceptance versus rejection, (2) psychological autonomy versus psychological control, and (3) firm control versus lax control. Building on this work, the work

\footnotetext{
* Corresponding author. Tel.: +1 801422 9053; fax: +1 8014220230.

E-mail address: laura_walker@byu.edu (L.M. Padilla-Walker).
} 
of Baumrind, Maccoby, Martin, and others began to formulate clusters of parents based on the dimensions of warmth/ responsiveness and demandingness/control (e.g., Baumrind, 1971; Baumrind \& Black, 1967; Darling \& Steinberg, 1993; Maccoby \& Martin, 1983). Taken together, it has been noted that the work that has been done on either dimensional approaches to parenting or broad typologies of parenting appears to reflect several important and distinguishing features of include (a) support shown to a child (e.g., acceptance, affection, involvement, nurturance) aimed at forming an emotional connection with the child, (b) behavioral control (e.g., limit setting, supervision, reasoning about consequences) of the child aimed at promoting mature behavior, and (c) autonomy granting (e.g., giving choice, allowing child input into rule making, permitting the expression of ideas, avoiding intrusive behavior) aimed at fostering emotional and psychological self-reliance (Hart, Newell, \& Olsen, 2003).

In examining these key aspects of parenting, researchers have not only found links with each dimension of parenting and child/adolescent outcomes (e.g., parental support linked to positive adjustment; Bean, Bush, McKenry, \& Wilson, 2003; Mounts, 2004), but have also identified potential combinations that appear to be more or less adaptive across childhood and adolescence. For example, parenting that reflects a combination of support and behavioral control has been linked to numerous indices of social, emotional, cognitive, and academic well-being and functioning from early childhood through adolescence (e.g., Aunola, Stattin, \& Nurmi, 2000; Bean, Barber, \& Crane, 2006; Eccles, Early, Frasier, Belansky, \& McCarthy, 1997; Hart, Yang et al., 1998; Isley, O’Neil, \& Parke, 1996; Steinberg, Lamborn, Darling, Mounts, \& Dornbusch, 1994).

Of particular interest for the present study are varying forms of parental control that have been identified. As noted previously, behavioral control refers to parental regulation and structuring of the child's behavioral world (e.g., homework, daily activities, manners), while psychological control refers to parental behaviors that are intrusive and manipulative of children's thoughts, feelings, and attachment to parents (e.g., invalidating feelings, love withdrawal, inducing guilt; Barber, 1996; Barber \& Harmon, 2002). As reported previously, when behavioral control is coupled with parental support intended to foster child maturity, it appears to be associated with child well-being (see Hart et al., 2003). However, when parental attempts to exercise coercive control are aimed at limiting children's behavioral autonomy (i.e., harsh, threatening, authoritarian behaviors) or psychological and emotional autonomy (i.e., psychological control), children and adolescents tend to exhibit problems of both externalizing and internalizing natures (e.g., Barber, 1996; Barber \& Harmon, 2002; Bean et al., 2006; Hart, Nelson, Robinson, Olsen, \& McNeilly-Choque, 1998; Olsen et al., 2002; Pettit, Clawson, Dodge, \& Bates, 1996).

Although these approaches certainly capture parenting that is low on autonomy granting, neither behavioral nor psychological control seems to quite capture the type of control, or involvement, that tends to typify the form of parenting coined "helicopter" or "hovering" parenting by pop culture (e.g., Gabriel, 2010). For example, recent articles in the New York Times portray parents who drop their children off at college and refuse to leave, attending classes with their children for the first week of school, intervening in roommate disputes, and calling professors or administrators when a child gets a lowerthan-expected grade (e.g., Gabriel, 2010; Marano, 2010). This tends to reflect parents who are highly invested, extremely concerned for the well-being of their children, and well-intentioned albeit misdirected.

In this sense, we are not proposing that helicopter parenting is an entirely new dimension of parenting. Instead, it represents a unique patterning of the basic dimensions of parenting. Specifically, it represents parenting that is high on warmth/support, high on control, and low on granting autonomy. In that regard, the popular notion of helicopter parenting appears to involve the same major dimensions of parenting (e.g., responsiveness/involvement, control, and autonomy granting) that comprise other forms of parenting (e.g., authoritative parenting, psychological control) but is unique in how those dimensions are prioritized. The distinction is made in that helicopter parenting does not appear to be a clear form of psychological control as it does not appear to target the emotional or psychological autonomy of the child. It certainly appears to reflect some aspects of behavioral control, but with high levels of warmth and support as well as excessive limiting of autonomy that is not at all consistent with the age of the child.

In these respects, helicopter parenting is reminiscent of similar constructs that have been identified in parenting of children at various ages. For example, helicopter parenting does share some characteristics with certain forms of psychological control that are driven by parental separation anxiety (e.g., Soenens, Vansteenkiste, Duriez, \& Goossens, 2006) and are specifically aimed at limiting adolescents' increasing separation and independence (e.g., Hock, Eberly, Bartle-Haring, Ellwanger, \& Widaman, 2001). For example, Soenens, Vansteenkiste, and Luyten (2010) suggest that dependency-oriented psychological control is reflective of intolerance of parent-child distance as parents make their warmth, love, and involvement conditional on the child remaining within close parent-child boundaries. However, this construct does not seem to capture the notion of helicopter parenting more generally or behaviorally as it appears to be more focused on the parents' well-being and security in its attempts to target the emotional and psychological well-being of the child.

More similarity exists between helicopter parenting in emerging adulthood and an approach to parenting of younger children known as overprotective, or oversolicitous parenting. In studying shy and socially withdrawn children, researchers have identified a form of parenting that includes intrusive and unnecessary micro-management of a child's independent activities, and strong affection in the absence of child distress or need for comforting (Rubin, Hastings, Stewart, Henderson, \& Chen, 1997). Oversolicitous parenting has repeatedly been linked with maladaptive outcomes (e.g., anxiety-related problems, social withdrawal/shyness, peer difficulties) in young children from ages 2 to 5 (e.g., Bayer, Sanson, \& Hemphill, 2006; McShane \& Hastings, 2009; Nelson et al., 2006; Rubin, Burgess, \& Hastings, 2002; Rubin et al., 1997; Rubin, Nelson, Hastings, \& Asendorpf, 1999). Given that involvement, protection, affection, etc. tend to be aspects of "good" parenting, it leads to the question of when and whether a parent can give too much of a "good" thing. Thomasgard and Metz (1993) suggest that the 
line that distinguishes between normative/appropriate protection and maladaptive overprotection is whether or not the situation or context of the parent-child interaction warrants such high levels of direction and affection from a parent. For example, it has been found that maternal solicitousness during free play is linked to child shy-reticent behaviors at age four whereas the same maternal behavior during a task that calls for mother involvement (i.e., a structured teaching task that was intentionally difficult for the child) was not associated with child problems (Rubin, Cheah, \& Fox, 2001). A social domain perspective is also enlightening in this regard, suggesting that parental discipline or involvement is seen as appropriate in response to misdeeds in some domains (i.e., moral, prudential), but is perceived as intrusive and controlling in other domains (i.e., personal; Nucci \& Weber, 1995; Padilla-Walker, 2008). Taken together, it appears that parental oversolicitous behavior is a problem because it reflects parental involvement, or control, when it is either developmentally or contextually inappropriate.

Given the amount of work examining this type of parenting and its associations with negative child outcomes in early childhood, it is noteworthy how scant the research on this construct is in samples of older children and adolescents (see Hastings, Nuselovici, Rubin, \& Cheah, 2010). Furthermore, it appears that the notion of inappropriate (for the developmental level of the child, the context, or the specific characteristics of the child) involvement, control, directiveness, and support captured by oversolicitous parenting is exactly what is reflected in the popular notion of helicopter parenting. Thus, despite the attention helicopter parenting has received in the popular media, there have been no scholarly attempts to identify it as a unique construct and to examine how it might be related to other more well-established dimensions of parenting.

\section{Parental control in emerging adulthood}

It would seem particularly important to study the effects of oversolicitous parenting in emerging adulthood because the very nature of the time period calls for greater amounts, not less, of autonomy granting by parents. Emerging adulthood has been deemed a period of time during which young people both desire and are working toward greater selfreliance in areas such as decision making and finances (e.g., Arnett, 2004). Indeed, emerging adults report that in order to become an adult one needs to accept responsibility for the consequences of one's own actions, begin to make decisions independent of parents, and become financially independent from parents (Arnett, 1998; Nelson \& Barry, 2005). However, before they have achieved these aspects of adulthood, they are left in a period of being "in-between" (Arnett, 2004, p. 8) which leads to a level of uncertainty regarding the child's status as an adult. For example, the majority of 18-25 year olds (i.e., emerging adults) in the United States do not consider themselves to be adults (e.g., Nelson \& Barry, 2005), nor do the majority of their parents view their children as adults (Nelson et al., 2007). As a result, many parents feel they still need and want to help their children navigate this period of experimentation and exploration, while at the same time allowing them the autonomy they want and need. It becomes a balancing act between fostering their emerging adult's strivings to gain more autonomy by fulfilling adult roles (Aquilino, 1996, 2006; Schnaiberg \& Goldenberg, 1989) with the support that is needed to successfully do so. Thus, it seems that attempts at control, or limiting autonomy, would be particularly harmful during emerging adulthood.

There is emerging evidence suggesting that, indeed, psychological and behavioral control are related to negative outcomes in emerging adulthood. In a study of parenting in emerging adulthood, Nelson and Padilla-Walker (2011) identified a cluster of mothers and fathers that scored high on indices of control - both behavioral and psychological control. The mothers who scored high on these indices of control had children with the most negative child outcomes in the study, with the lowest levels of parent-child closeness and child self-worth, and the highest levels of child depression, anxiety, and impulsivity. Likewise, children of more controlling fathers were consistently rated as having the worst child outcomes, with the lowest levels of parent-child closeness, child self-worth, and kindness; and the highest levels of child depression and anxiety. In another study of emerging adults and their mothers, maternal psychological control negatively predicted child satisfaction with the relationship with mother and child disclosure to mother, and positively predicted child participation in risk behaviors (Urry, Nelson, \& Padilla-Walker, 2011). Finally, Luyckx, Soenens, Vansteenkiste, Goossens, and Berzonsky (2007) have found psychological control to be detrimental in the process of emerging adults' identity formation.

Taken together, it appears that attempts at control are linked to negative child outcomes in emerging adulthood. While the link between psychological control and negative outcomes are not necessarily surprising given the plethora of similar findings in childhood and adolescence (see Barber, 2002), the findings, albeit scant, regarding behavioral control are somewhat unexpected. Behavioral control, particularly in combination with parental support, tends to be associated with higher levels of psychosocial functioning during the formative years (see Barber, Stolz, \& Olsen, 2005). However, there is evidence that as children get older (i.e., adolescence), when greater levels of autonomy might be expected, high levels of both support and control have been found to predict risky peer context and problem behaviors (Goldstein, Davis-Kean, \& Eccles, 2005). Thus, it may be that any form of parental control that attempts to limit autonomy might become increasingly problematic, especially as one reaches emerging adulthood. However, as noted previously, only a few attempts have been made to examine the links between behavioral control and psychological control in emerging adulthood, and no study has sought to identify oversolicitous, or helicopter, parenting in emerging adulthood and its possible links with child outcomes. Thus, the purpose of the current study was to establish a measure of helicopter parenting and (a) examine whether this construct is distinguishable from behavioral and psychological control in emerging adulthood, and (b) examine its correlates with general dimensions of parenting, other aspects of the parent-child relationship, and child adjustment outcomes. 


\section{Current study}

Based on the work reviewed previously on oversolicitous parenting in young children, we developed the following hypotheses regarding the first purpose of the study (i.e., distinguishing helicopter parenting from behavioral and psychological control in emerging adulthood). We expected that psychological control, behavioral control, and helicopter parenting would emerge as distinct, albeit related, forms of parental control. As there are no existing measures for helicopter parenting in emerging adulthood, we built on the conceptual notion that helicopter parenting would reflect support as well as control, and drew from empirical (e.g., oversolicitous parenting in childhood; see Burgess, Rubin, Cheah, \& Nelson, 2001; Nelson et al., 2006) and popular sources to develop items for the study intended to tap the dimensions of this form of parenting (i.e., inappropriate control and involvement such as solving problems and making decisions for emerging adult children). These items were added to a parenting measure of established ratings of psychological control and behavioral control. It was predicted that each form of parental control would emerge as a distinct construct as reflected in (a) separate factors emerging when subjected to factor analysis, and (b) the level of correlations between the factors being significant, but not completely overlapping.

In examining the links between helicopter parenting and other parenting dimensions we chose to examine parental warmth, involvement, and autonomy granting because these constructs have been shown to reflect several important and distinguishing features of parenting (Hart et al., 2003). Furthermore, when combined at the levels of high warmth and involvement and low autonomy granting, they are believed in both empirical (e.g., oversolicitous parenting in childhood; see Burgess et al., 2001; Nelson et al., 2006) and popular sources to be characteristics of helicopter parents. Therefore, we hypothesized that helicopter parenting would be positively associated with warmth and involvement but negatively related to autonomy granting.

In examining the relations between helicopter parenting and aspects of the parent-child relationship, we chose to examine child perceptions of the parent-child relationship including the extent to which the child felt guidance, affection, and emotional support from the relationship, as well as the ability to self-disclose in the relationship. These variables were chosen because we believed they might shed light on the context (i.e., the relationship) in which helicopter parenting might be taking place. We found it difficult to make specific hypotheses given the lack of existing research in this regard, but the proposed controlling component of helicopter parenting led us to believe that helicopter parenting could be positively associated with guidance and disclosure, as children used to high levels of parental control tend to have difficulty making independent decisions (Hart et al., 2003). In turn, given the proposed component of warmth and concern in helicopter parenting, we thought this form of parenting might be positively linked to affection and emotional support, although we also thought it possible that the controlling portion of this parental approach might overshadow the warmth (Nelson et al., 2011), which may result in negative associations with affection and emotional support.

Finally, to explore the correlates between helicopter parenting and child outcomes, we elected to examine self-worth, school engagement, perceived adult status, and identity achievement. We chose to examine self-worth as there is evidence suggesting that psychological control is particularly harmful in the development of a child's psychological self (see Barber \& Harmon, 2002). Hence we deemed it important to examine how helicopter parenting might be linked with this important aspect of development in emerging adulthood. Similarly, identity development, coming to see oneself as a selfreliant individual (i.e., adult), and pursuing an education/career have all been identified as important aspects of emerging adulthood (e.g., Arnett, 2004). Therefore, we thought it important to examine the associations between helicopter parenting and these important aspects of emerging adulthood. Given that, conceptually, it is believed that helicopter parents are controlling and overly involved in their emerging adults' lives, it was hypothesized that these parents would be hindering the process of the children becoming autonomous, self-reliant individuals as evidenced by lower levels of feeling like an adult, identity development, self-worth, and school engagement.

\section{Methods}

\section{Participants}

Participants for this study were drawn from a study of emerging adults and their parents entitled Project READY (Researching Emerging Adults' Developmental Years), which is an ongoing, collaborative, multi-site study that is being conducted by a consortium of developmental and family scholars. Data used in the current study were collected during the 2010-2011 academic year. The sample for the current study $\left(M_{\mathrm{age}}=19.65, \mathrm{SD}=2.00\right.$, range $\left.=18-29\right)$ consisted of 438 undergraduate students (320 women, 118 men) and at least one of their parents (376 mothers, 303 fathers). Thirty-nine percent of participants were in their first year of college, $28 \%$ were in their second year, $18 \%$ were in their third year, and $15 \%$ were in their fourth year or beyond. Participants were recruited from four universities across the United States, including large public universities in the Western, Mid-Western, and Southern United States, as well as a private university in the Eastern United States. Response rate varied by site (ranging from 50 to 71\%), with an overall response rate of approximately 60\%.

The majority of emerging adults were European American (69\% European American, 3\% African American, 18\% Asian American, 5\% Latino American, and 5 mixed/biracial). Ninety percent of emerging adults reported living outside of their parents' home in an apartment, house, or dormitory. Ten percent reported living in their parents' home. Sixty percent of fathers and fifty-five percent of mothers reported having a bachelor's degree or more, $23 \%$ of parents reported having a combined income of less than $\$ 50,000$ per year, and $28 \%$ reported a combined income of over $\$ 100,000$. 


\section{Procedure}

Participants completed the Project READY questionnaire via the Internet (www.projectready.net). The use of an online data collection protocol facilitated unified data collection across multiple university sites and allowed for the survey to be administered to emerging adults and their parents who were living in separate locations throughout the country. Participants were recruited through faculty's announcement of the study in undergraduate courses. Undergraduate courses were primarily Introduction to Psychology courses or large general education courses of the like in an attempt to access a broad range of students. Professors at the various universities were provided with a handout to give to their students that had a brief explanation of the study and directions for accessing the online survey. Interested students then accessed the study website with a class-specific recruitment code. Informed consent was obtained online, and only after consent was given could the participants begin the questionnaires. Each participant was given a survey that took approximately 45 min to complete. Most participants were given a \$20 Amazon gift code for their participation, while a small portion (17\%) participated for extra credit. After participants completed the personal information, they had the option to send an invitation (via e-mail) to their parents to participate in the study. Parents completed a short questionnaire that took approximately 15 min, asking them to respond to many of the same questions as did their child, but from a parental point of view. Parents were each given a $\$ 10$ Amazon gift code for their participation.

\section{Measures}

\section{Helicopter parenting}

Helicopter parenting was assessed using five items written for the current study to assess the degree to which parents make important decisions for their emerging adult children. Emerging adults and their parents answered questions on a 5point scale ranging from 1 (not at all like me/him/her) to 5 (a lot like me/him/her). Items used were, "My parent makes important decisions for me (e.g., where I live, where I work, what classes I take)", "My parent intervenes in settling disputes with my roommates or friends", "My parent intervenes in solving problems with my employers or professors", "My parent solves any crisis or problem I might have", and "My parent looks for jobs for me or tries to find other opportunities for me (e.g., internships, study abroad, etc)". Items given to parents were slightly reworded to reflect how parents respond to their child (e.g., "I make important decisions for my child"). Reliability indices and results from exploratory factor analyses are reported in the results section.

\section{Behavioral control}

Behavioral control was assessed using five items assessing parents' tendency to control their child's friends, money, or activities (Kerr \& Stattin, 2000). Emerging adults and their parents answered questions on a 5-point scale ranging from 1 (not at all like me/him/her) to 5 (a lot like me/him/her). Sample items include, "My parent tries to set rules about what I do with my free time," and "My parent tries to tell me what I can and can't do on nights and weekends." Items given to parents were slightly reworded to reflect how parents respond to their child. Higher scores indicated higher levels of child-reported mother ( $\alpha=.89)$ and father $(\alpha=.87)$, as well as mother- $(\alpha=.89)$ and father- $(\alpha=.89)$ reported behavioral control. In the final SEM models, a latent variable was created using all four reports of behavioral control.

\section{Psychological control}

Psychologically control was assessed using four items assessing psychological controlling parenting (Barber, 1996). In their work on psychological control, Morris et al. (2002) have argued for the use of child-reports of their parents' behaviors because "only by evaluating parenting through the child's subjective experience can researchers truly understand the impact of the social context on children's psychosocial adjustment” (p. 132). Barber (2002) has likewise argued that "psychological control and its effects will likely always be measured in part by the recipients of it" (p. 27). Therefore, we chose to have emerging adults report on their parents' psychological control. Specifically, emerging adults answered questions on a 3-point scale ranging from 1 (not at all like him/her) to 3 (a lot like him/her). Sample items include, "If I have hurt his/her feelings, my parent stops talking to me until I please him/her again," and "My parent will avoid looking at me when I have disappointed her/him." Higher scores indicated higher levels of child-reported mother $(\alpha=.83)$ and father $(\alpha=.81)$ psychological control. In the final SEM models, a latent variable was created using child reports of mother and father psychological control.

\section{Parenting dimensions}

Parenting was assessed using the warmth, involvement, and autonomy support subscales of the Perception of Parents Scale (POPS): College Student Version (Grolnick, Ryan, \& Deci, 1991; Robbins, 1994). Emerging adults and their parents answered questions on a 7-point scale ranging from 1 (not at all true) to 7 (very true). Sample questions include, "My parent finds time to talk with me" for warmth ( 6 items, child-report mother, $\alpha=.86$; child-report father, $\alpha=.89$; mother-report, $\alpha=.69$; father-report, $\alpha=.81$ ), "My parent spends a lot of time with me" for involvement (6 items, child-report mother, $\alpha=.80$; child-report father, $\alpha=.85$; mother-report, $\alpha=.69$; father-report, $\alpha=.70$ ), and "My parent helps me to choose my own direction" for autonomy support ( 8 items, child-report mother, $\alpha=.85$; child-report father, $\alpha=.87$; mother-report, $\alpha=.76$; father-report, $\alpha=.72$ ). In the final SEM model, latent variables were created using all four reports to represent parental warmth, parental involvement, and parental autonomy support. 


\section{Parent-child relationship}

The parent-child relationship was assessed using four subscales (guidance/advice, disclosure, affection, and emotional support) from the Social Provisions Questionnaire (Carbery \& Buhrmester, 1998). Emerging adults answered questions on a 5point scale ranging from 1 (little or none) to 5 (the most). Sample questions include, "How often do you depend on this person for help, advice, or sympathy?" for guidance/advice ( 3 items, $\alpha=.86$ mother; $\alpha=.89$ father), "How often do you talk to this person about things that you don't want others to know?" for disclosure ( 3 items, $\alpha=.89$ mother; $\alpha=.90$ father), "How much does this person like or love you?" for affection ( 3 items, $\alpha=.85$ mother; $\alpha=.91$ father), and "How often do you turn to this person for support with personal problems?" for emotional support ( 3 items, $\alpha=.90$ mother; $\alpha=.96$ father). In the final SEM model, child-reports for mother and father were averaged to represent overall parental guidance, disclosure, affection, and support.

\section{Self-worth}

Self-worth was assessed using five items from the Self Perceptions Profile for College Students (Neeman \& Harter, 1986). Emerging adults responded on a 4-point scale ranging from 1 (not at all true for me) to 4 (very true for me). Sample questions include, "I am often disappointed with myself (reverse scored)," and "I am happy being the way I am." Higher scores represented higher feelings of self-worth $(\alpha=.84)$.

\section{School engagement}

School engagement was assessed using three items assessing emerging adults' commitment to education (Fredericks, Blumenfeld, \& Paris, 2005). Emerging adults responded on a 5-point Likert scale ranging from 1 (not like me at all) to 5 (very much like me). Sample questions include, "I complete my homework/assignments on time" and "I regularly attend my classes." Higher scores represented greater school engagement $(\alpha=.83)$.

\section{Perceptions of adulthood and identity}

Perceptions of adulthood were assessed by asking emerging adults: "Do you think that you have reached adulthood?" Response options included $1=($ no), 2 = (in some respects yes, in some respects no), and $3=$ (yes). This method of adult status classification has been used elsewhere, and has demonstrated adequate face validity (e.g., Nelson \& Barry, 2005). Identity was assessed using 12 items from the Ego Identity Scale (Balistreri \& Busch-Rossnagel, 1995), which assesses identity (exploration and commitment) in the domains of occupation, dating, and values/beliefs. Emerging adults answered items on a 6-point scale ranging from 1 (strongly disagree) to 6 (strongly agree). Sample questions include, "My values are likely to change in the future," and "My beliefs about dating are firmly held." Items were reverse scored where necessary and summed across domains so high scores represented higher overall levels of identity achievement $(\alpha=.64)$. Although this alpha value is relatively low, this was not unexpected given that the items were assessing different domains of identity.

\section{Results}

Factor analysis and intercorrelations between types of parental control

We conducted a factor analysis using oblique rotation (separately for all reports) on helicopter parenting, behavioral control, and psychological control (for child-reports only) to determine if aspects of control were distinguishable from one another. Results for child-reports of mothers and fathers revealed three distinct factors with Eigenvalues above 1.0, with the behavioral control items loading on the first factor (35\% of variance for mothers, 36\% for fathers), helicopter parenting items loading on the second factor (17\% of variance for mothers, $17 \%$ for fathers), and psychological control items loading on the third factor ( $10 \%$ of variance for mothers, $10 \%$ for fathers). Factor loadings on helicopter parenting items ranged from .49 to .89 (see Table 1), and none of the items cross loaded on other factors with values above .40. Results for mothers' and fathers' reports of helicopter parenting and behavioral control revealed two distinct factors with Eigenvalues above 1.0, with the helicopter parenting items loading on the first factor (51\% of variance for mothers, $48 \%$ for fathers) and behavioral control items loading on the second factor (15\% of variance for mothers, $16 \%$ for fathers). Factor loadings on helicopter parenting items ranged from .40 to .93 (see Table 1), and four of the five items did not cross load on other factors with values above .40 . However, for both mother- (.41) and father- (.53) reports, one item ("I make important decisions for my child") loaded above .40 on the behavioral control factor. In addition, reliability analyses were conducted and indicated adequate reliability for child-reported mother $(\alpha=.87)$ and father $(\alpha=.84)$, as well as mother- $(\alpha=.77)$ and father- $(\alpha=.78)$ reported helicopter parenting. It should also be noted that we conducted 1- and 3-factor solutions (2-factor for parent-report) in AMOS for individual items, separately for each reporter. In every instance, the 3-factor solution had significantly better model fit than did the 1 -factor solution.

To examine intercorrelations between types of control, we created three latent variables (one for each parental control construct) using child's report of mother and father, and mother- and father-reports for helicopter parenting and behavioral control; and using child's report of mother and father for psychological control. It should be noted that non-independence of data as a function of multiple constructs with the same reporter was addressed by correlating error terms from the same reporter. Analyses were conducted using Analysis of Moments Structure (AMOS) software (Arbuckle, 2010). For all analyses, we used the Full Information Maximum Likelihood feature of AMOS to handle missing data, with $5 \%$ or less missing data on all 
Table 1

Factor loadings on all reports of parental control.

\begin{tabular}{|c|c|c|c|c|}
\hline Item & $\begin{array}{l}\text { Child-report } \\
\text { mother }\end{array}$ & $\begin{array}{l}\text { Child-report } \\
\text { father }\end{array}$ & Mother-report & Father-report \\
\hline \multicolumn{5}{|l|}{ Helicopter parenting } \\
\hline $\begin{array}{l}\text { 1. Makes important decisions for me (e.g., where I live, where I } \\
\text { work, what classes I take) }\end{array}$ & .50 & .50 & .53 & .40 \\
\hline 2. Intervenes in settling disputes with my roommates or friends & .85 & .79 & .88 & .79 \\
\hline 3. Intervenes in solving problems with my employers or professors & .89 & .86 & .93 & .86 \\
\hline 4. Solves any crisis or problem I might have & .81 & .85 & .76 & .83 \\
\hline $\begin{array}{l}\text { 5. Looks for jobs for me or tries to find other opportunities } \\
\text { for me (e.g., internships, study abroad) }\end{array}$ & .49 & .60 & .64 & .73 \\
\hline \multicolumn{5}{|l|}{ Behavioral control } \\
\hline 1. Tries to limit or control who my friends are & .83 & .80 & .83 & .82 \\
\hline 2. Tries to set rules about what I do with my free time & .80 & .86 & .93 & .87 \\
\hline 3. Tries to tell me what I can and can't do on nights and weekends & .82 & .85 & .85 & .87 \\
\hline 4. Tries to control how I spend my money & .77 & .77 & .84 & .81 \\
\hline $\begin{array}{l}\text { 5. Tries to control which classes I take or what my major is } \\
\text { Psychological control } \\
\text { My parent... }\end{array}$ & .73 & .75 & .65 & .72 \\
\hline 1. Brings up past mistakes when $\mathrm{s} /$ he criticizes me & .78 & .73 & - & - \\
\hline 2. Is less friendly with me if I do not see things his/her way & .83 & .86 & - & - \\
\hline 3. Will avoid looking at me when I have disappointed him/her & .78 & .81 & - & - \\
\hline 4. If I have hurt his/her feelings, stops talking to me until I please him/her & .84 & .82 & - & - \\
\hline
\end{tabular}

variables in the final models. Analyses revealed that all four reports of helicopter parenting loaded on one latent variable (factor loadings ranged from .43 to .91), all four reports of behavioral control loaded on one latent variable (factor loadings ranging from .50 to .88 ), and both reports of psychological control loaded on one latent variable (factor loadings were .57 and .62 ). The data fit the model well, $X^{2}(18)=56.72, p<.001, \mathrm{CFI}=.98$, RMSEA $=.07$. It should also be noted that the 3 -factor solution was compared to a 1 -factor solution (where all reports of parental control were placed on a single factor) and model fit decreased significantly ( $X^{2}$ difference $=96.08, p<.001$, with factor loadings ranging from .25 to .65 ), further supporting evidence for three separate constructs. Correlations between latent variables suggested that helicopter parenting was associated with both behavioral $(.59, p<.001)$ and psychological $(.43, p<.001)$ control, and that behavioral and psychological control were significantly associated with one another $(.60, p<.001)$. These analyses confirmed that these three aspects of control are certainly interrelated, but not completely overlapping.

\section{Descriptive statistics and correlations}

We conducted a repeated-measures analysis of variance (ANOVA) on the four reports of helicopter parenting to determine if there were significant mean differences between reporters, $\left(F(3,243)=11.99, p<.001, \eta p^{2}=.13\right)$. LDS post-hoc follow-ups revealed that child-report of father was lower $(M=1.99, \mathrm{SD}=.77)$ than fathers' self-report $(M=2.25, \mathrm{SD}=.86)$, mothers' selfreport $(M=2.23, \mathrm{SD}=.80)$, and child-report of mother $(M=2.14, \mathrm{SD}=.82)$. We conducted additional repeated-measures ANOVAs to determine if child-report of the mean level of helicopter parenting differed from mean levels of child-reported behavioral and psychological control. In order to compare measures that were not on the same scale, we put scores on the same scale (a 15-point scale) by multiplying helicopter parenting and behavioral control by 3 (these measures were on a 5point scale) and multiplying psychological control by 5 (this measure was on a 3-point scale). Using these transformed variables, analyses reveled a significant difference in both mothers' $\left(F(2,436)=36.43, p<.001, \eta p^{2}=.14\right)$ and fathers' $(F(2$, $433)=48.76, p<.001, \eta p^{2}=.18$ ) approaches to control. LDS follow-ups revealed that for child-report of mothers there was no difference between the use of helicopter parenting $(M=6.01, \mathrm{SD}=2.43)$ and behavioral control $(M=6.03, \mathrm{SD}=2.68)$, but that mothers' use of psychological control $(M=7.24, \mathrm{SD}=2.76)$ was more common than both other forms of control. For child-report of fathers, helicopter parenting $(M=5.52, \mathrm{SD}=2.30)$ was used less frequently than was behavioral control $(M=5.77, \mathrm{SD}=2.65)$; and psychological control $(M=7.01, \mathrm{SD}=2.65)$ was more common than both other forms of control. Correlations between helicopter parenting and all other study variables are presented in Table 2. It is of particular note that associations between variables of interest differed as a function of reporter. That being said, all reports of helicopter parenting were associated (at moderate levels) with corresponding reports of behavioral and psychological control.

\section{Relations between helicopter parenting and emerging adults' relational and behavioral outcomes}

Using AMOS software, we conducted three structural models to determine how helicopter parenting was related to outcomes. It should be noted that because helicopter parenting was the focus of this study, and due to our prior analyses establishing helicopter parenting, behavioral control, and psychological control as distinct constructs, the remainder of the 
Table 2

Correlations between helicopter parenting and all study variables.

\begin{tabular}{|c|c|c|c|c|}
\hline & \multicolumn{4}{|c|}{ Helicopter parenting } \\
\hline & MR & FR & CRM & CRF \\
\hline Behavioral control MR & $.57^{* * *}$ & $.24^{* * *}$ & $.25^{* * *}$ & $.22^{* * *}$ \\
\hline Behavioral control FR & $.23^{* * *}$ & $.54^{* * *}$ & $.21^{* * *}$ & $.21^{* * *}$ \\
\hline Behavioral control CRM & $.23^{* * *}$ & $.24^{* * *}$ & $.50^{* * *}$ & $.42^{* * *}$ \\
\hline Behavioral control CRF & $.23^{* * *}$ & $.23^{* * *}$ & $.43^{* * *}$ & $.52^{* * * *}$ \\
\hline Psychological control CRM & $.10^{*}$ & $.16^{* *}$ & $.13^{* *}$ & .06 \\
\hline Psychological control CRF & $.11^{*}$ & $.12^{*}$ & $.14^{* *}$ & $.14^{* *}$ \\
\hline Warmth MR & $-.12^{*}$ & -.01 & -.05 & .01 \\
\hline Warmth FR & -.07 & .08 & .02 & .09 \\
\hline Warmth CRM & -.04 & .01 & -.02 & .01 \\
\hline Warmth CRF & -.03 & -.03 & -.03 & .08 \\
\hline Involvement MR & -.02 & $.14^{*}$ & .03 & .07 \\
\hline Involvement FR & .03 & $.18^{* *}$ & .10 & $.19^{* * *}$ \\
\hline Involvement CRM & -.01 & .05 & $.12^{*}$ & $.11^{*}$ \\
\hline Involvement CRF & .01 & .04 & .08 & $.20^{* * *}$ \\
\hline Autonomy granting MR & $-.31^{*}$ & -.06 & $-.13^{* *}$ & -.04 \\
\hline Autonomy granting FR & -.11 & -.05 & -.07 & -.01 \\
\hline Autonomy granting CRM & $-.14^{* *}$ & -.04 & $-.12^{* *}$ & -.07 \\
\hline Autonomy granting CRF & $-.11^{*}$ & -.06 & $-.10^{*}$ & -.01 \\
\hline Guidance/advice CRM & .05 & $.12^{*}$ & $.13^{* *}$ & $.12^{*}$ \\
\hline Guidance/advice CRF & .05 & .07 & $.11^{*}$ & $.25^{* * *}$ \\
\hline Disclosure CRM & .04 & .10 & $.13^{* *}$ & $.12^{*}$ \\
\hline Disclosure CRF & .05 & .04 & $.11^{*}$ & $.25^{* * *}$ \\
\hline Affection CRM & -.06 & .04 & .00 & .03 \\
\hline Affection CRF & -.05 & -.02 & .01 & $.15^{* *}$ \\
\hline Emotional support CRM & .00 & .08 & .03 & .05 \\
\hline Emotional support CRF & .00 & .03 & .06 & $.19^{* * *}$ \\
\hline Self-worth & .00 & -.01 & -.08 & -.05 \\
\hline School engagement & $-.11^{*}$ & $-.14^{*}$ & $-.19^{* * *}$ & $-.17^{* * * *}$ \\
\hline Adult status & .06 & .07 & .05 & .06 \\
\hline Identity & -.04 & -.07 & $-.10^{*}$ & $-.10^{*}$ \\
\hline
\end{tabular}

Note. MR = mother-report, FR = father-report, CRM = child's report of mother, CRF = child's report of father.

${ }^{*} p<.05,{ }^{* *} p<.01,{ }^{* * *} p<.001$.

structural equation models were conducted with only helicopter parenting predicting outcomes (i.e., behavioral and psychological control were not included). We used child's age and gender as controls in the model, but they are not shown in the figures for parsimony. The first model examined relations between helicopter parenting and more general aspects of parenting including parental warmth, involvement, and autonomy granting. The second model examined relations between helicopter parenting and the parent-child relationship, including whether the child relied on the parents for guidance/advice, disclosure, affection, and emotional support. The third model examined relations between helicopter parenting and emerging adult behavioral outcomes, including self-worth, school engagement, perceptions of adulthood, and identity achievement.

For the first model predicting general aspects of parenting, we conducted a structural model (see Fig. 1) and it displayed adequate model fit, $X^{2}(104)=395.41, p<.001, C F I=.94$, RMSEA $=.08$. Factor loadings on endogenous variables ranged from .57 to .78 . Results revealed that helicopter parenting was positively associated with parental involvement $(\beta=.19, p<.01)$, and negatively associated with parental autonomy granting $(\beta=-.12, p<.05)$. It should be noted that age was unrelated to parenting outcomes, but gender (male $=0$, female $=1$ ) was positively related to warmth $(\beta=.13, p<.001$ ), involvement $(\beta=.17, p<.001)$; and autonomy granting $(\beta=.15, p<.001)$.

For the second model examining the parent-child relationship, we conducted a structural model, and it displayed adequate fit, $X^{2}(21)=65.31, p<.001, \mathrm{CFI}=.97$, RMSEA $=.07$ (see Fig. 2 ). Results revealed that helicopter parenting was positively associated with guidance/advice $(\beta=.21, p<.001)$, disclosure $(\beta=.20, p<.001)$, and emotional support $(\beta=.10$, $p<.05)$. Age was not significantly associated with any relationship outcomes, but gender $($ males $=0$, females $=1)$ was positively associated with guidance $(\beta=.20, p<.001)$ and disclosure $(\beta=.11, p<.01)$.

For the third model examining emerging adult outcomes, we conducted a structural model and it displayed adequate fit, $X^{2}(21)=48.45, p<.001, \mathrm{CFI}=.97, \mathrm{RMSEA}=.06$ (see Fig. 3 ). Results revealed that helicopter parenting was negatively associated with school engagement $(\beta=-.19, p<.001)$. It should also be noted that age was positively associated with perceptions of adulthood $(\beta=.29, p<.001)$ and identity $(\beta=.19, p<.001)$; and gender $($ males $=0$, females $=1)$ was positively associated with school engagement $(\beta=.09, p<.05)$ and identity $(\beta=.15, p<.01)$, but negatively associated with perceptions of adulthood $(\beta=-.10, p<.05)$.

\section{Discussion}

The purpose of the current study was to establish a measure of helicopter parenting and (a) examine whether this construct is distinguishable from behavioral and psychological control in emerging adulthood, and (b) examine its correlates 


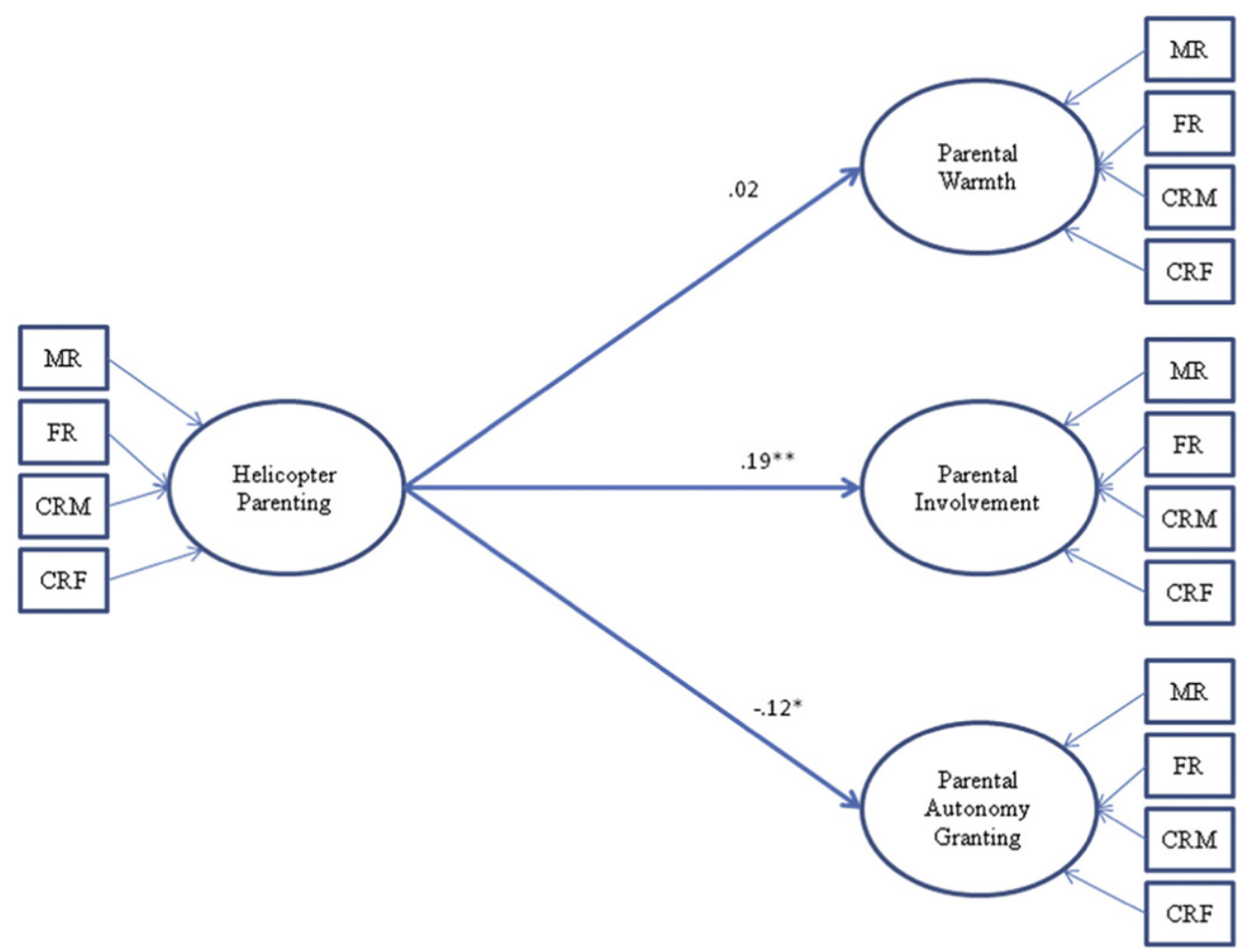

Fig. 1. Relations between helicopter parenting and parenting dimensions. Note. Latent variable and endogenous error correlations are omitted from the figure for parsimony. Paths represent standardized beta weights. $X^{2}(104)=395.41, p<.001, \mathrm{CFI}=.94$, RMSEA $=.08$. MR $=$ mother-report, $\mathrm{FR}=$ father-report, $\mathrm{CRM}=$ child's report of mother, CRF $=$ child's report of father. ${ }^{*} \mathrm{p}<.05,{ }^{* *} p<.01,{ }^{* * *} p<.001$.

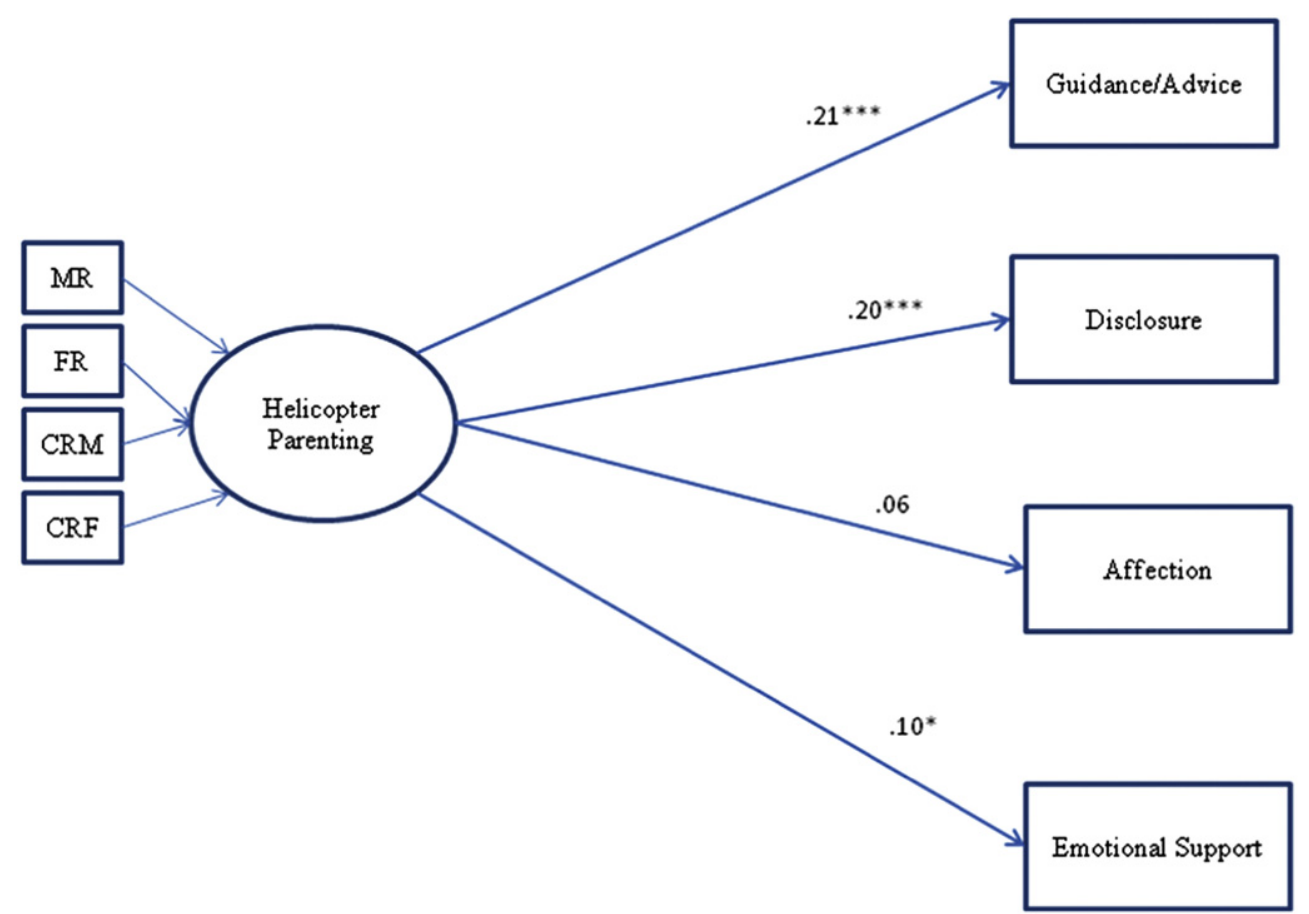

Fig. 2. Relations between helicopter parenting and the parent-child relationship. Note. Latent variable and endogenous error correlations are omitted from the figure for parsimony. Paths represent standardized beta weights. $X^{2}(21)=65.31, p<.001$, CFI $=.97$, RMSEA $=.07$. MR $=$ mother-report, FR $=$ father-report, $\mathrm{CRM}=$ child's report of mother, $\mathrm{CRF}=$ child's report of father. ${ }^{*} p<.05,{ }^{* *} p<.01,{ }^{* * *} p<.001$. 


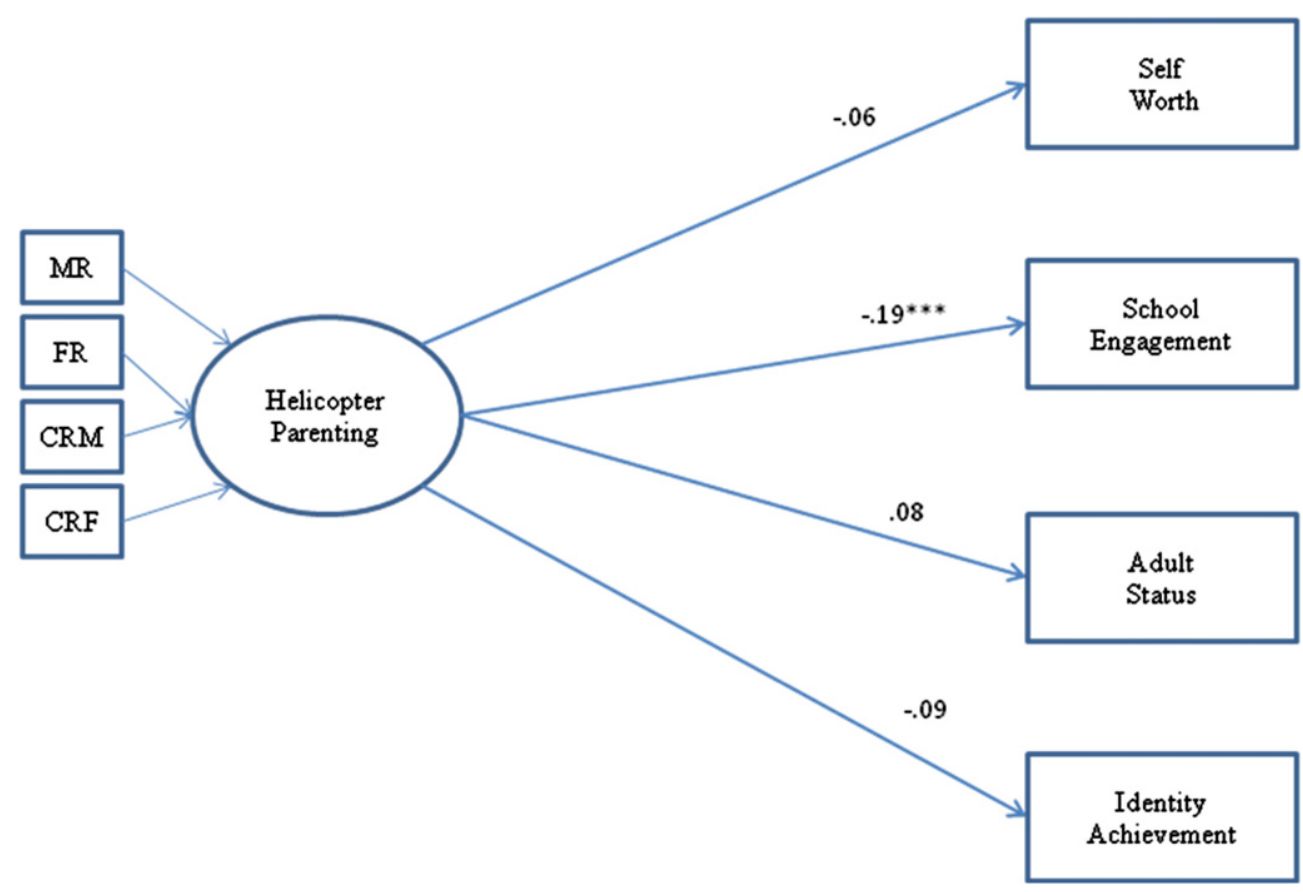

Fig. 3. Relations between helicopter parenting and emerging adult behavioral outcomes. Note. Latent variable and endogenous error correlations are omitted from the figure for parsimony. Paths represented standardized beta weights. $X^{2}(21)=48.45, p<.001, \mathrm{CFI}=.97$, RMSEA $=.06$. MR $=$ mother-report, FR $=$ fatherreport, $\mathrm{CRM}=$ child's report of mother, $\mathrm{CRF}=$ child's report of father. ${ }^{*} p<.05,{ }^{* *} p<.01,{ }^{* * *} p<.001$.

with general dimensions of parenting, other aspects of the parent-child relationship, and child adjustment outcomes. The first important set of findings suggested that helicopter parenting emerged as a distinct form of control in emerging adulthood. Results of factor analyses using items from child-reports revealed that helicopter parenting emerged as a factor separate from behavioral control and psychological control for both mothers and fathers. Using mother-reports and fatherreports, respectively, factor analyses also yielded two-factor results with helicopter parenting and behavioral control emerging on separate factors (parent-reports did not include items reflecting psychological control). Reliability analyses of and correlations among the parenting factors also pointed to strong constructs that were interrelated (as all measured some aspect of control) but distinct approaches to parental control. The second important set of findings that emerged was that helicopter parenting was positively associated with parental involvement and specific aspects of the parent-child relationship including guidance, disclosure, and emotional support, as well as negatively related to parental autonomy granting and emerging adults' school engagement.

Taken together, these findings make a significant contribution to our understanding of parenting in emerging adulthood because, while the term "helicopter" parenting has been used in popular culture for some time now, these results present some of the first empirical evidence that there is indeed an approach to parenting that reflects high levels of parental involvement in the lives of their emerging-adult children. This form of parenting appears to differ from behavioral control and psychological control, however, in many important and complex ways. Whereas both behavioral control and psychological control have been found to be inversely linked to positive aspects of parenting and the parent-child relationship in both adolescence (e.g., warmth, autonomy, affection, involvement, guidance/advice, and support; see Barber et al., 2005; Hart et al., 2003 for reviews) and emerging adulthood (Nelson et al., 2011), helicopter parenting appears to be related to both positive and negative aspects of the parent-child relationship. Indeed, children of helicopter parents appeared to see their parents in terms of a relationship high in guidance, involvement, and emotional support but likewise acknowledged a lack of autonomy being granted them by their parents. In general, it appears to reflect more of the characteristics of overprotective, or oversolicitous parenting that has been studied in early childhood (see Hastings et al., 2010). That is, helicopter parenting appears to be inappropriately intrusive and managing, but done out of strong parental concern for the well-being and success of the child.

Thus, one of the important contributions of this study is in demonstrating that while inappropriately intrusive (for reasons to be discussed below), helicopter parenting appears to differ from the control captured in both behavioral and psychological control. In making this important distinction, however, we would like several important points to be clear. First, to reiterate, we are not suggesting that helicopter parenting is an entirely new dimension of parenting. It still shares in common the major dimensions of parenting (e.g., responsiveness/involvement, control, and autonomy granting) as do other forms of parenting (e.g., authoritative parenting, psychological control). However, results of the study demonstrate that the way in which these dimensions are prioritized (high involvement, low autonomy granting, presence of emotional support in the relationship) 
reflects a uniquely distinguishable approach to parenting. Likewise, we are not suggesting it is a new form of parenting that appears in emerging adulthood. We believe it is akin to the concept of "oversolicitous" parenting identified and studied as early as, and almost exclusively in, early childhood (see Hastings et al., 2010). The term "helicopter" parenting is employed rather than oversolicitous parenting because the term is well entrenched in popular vernacular.

Finally, in stressing that our results demonstrate that helicopter parenting appears to differ from the control captured in both behavioral and psychological control, it is not meant to suggest that helicopter parenting is necessarily positive. In attempting to interpret our results in the context of the extant research on other forms of control, one might be led to propose that controlling parenting in the absence of warmth or emotional support (psychological control in particular) may be potentially more destructive than helicopter parenting given the positive feelings young people have about certain aspects of the relationship with their parents (e.g., guidance, emotional support). However, the harm caused by helicopter parenting may be just as growth-inhibiting but via different mechanisms.

Specifically, of oversolicitous parenting, it has been said that it may inhibit children's ability to develop the skills and abilities needed to act on one's own as they become more dependent upon external sources of support for effective functioning (Hastings et al., 2010). Most of the work that has been done examining oversolicitous parenting has been done in early childhood (see Hastings et al., 2010). While much of this work has examined the effect of intrusive parenting on preschoolers' ability to learn to regulate their emotions (e.g., Rubin et al., 2002), we start to see how similar processes might be at work in emerging adulthood. Indeed, it is believed that one way in which oversolicitous parenting harms children is by limiting opportunities to practice important skills and abilities (Hastings et al., 2010). Thus, in emerging adulthood, if parents repeatedly make decisions and solve problems (with roommates, employers, professors) for their children, it would limit the children's opportunities to practice the skills needed to flourish in emerging adulthood, successfully take on adult roles, and in general, become a self-reliant individual. It is important to note that in the present study helicopter parenting was neither positively nor negatively linked to identity achievement, feeling like an adult, or self-worth, supporting the notion that while it may not be directly destructive (like behavioral or psychological control, e.g., Luyckx et al., 2007), helicopter parenting may not be conducive to growth during emerging adulthood. Further evidence for the growth-inhibiting nature of helicopter parenting is found in the negative association between helicopter parenting and child's school engagement.

Indeed, it is interesting that the more parents are involved in the daily lives of their children, the less engaged young people are in school. Emerging adults with intrusive parents may take less of a proactive, personally invested approach to the important tasks of emerging adulthood such as pursuing an education/career. As noted previously, Thomasgard and Metz (1993) suggested that the line that separates normative/appropriate protection and maladaptive overprotection is whether or not the situation or context of the parent-child interaction warrants such high levels of direction and affection from a parent. Given that emerging adulthood has been characterized as a period of self-exploration, self-focus, and, in general, learning how to become self-reliant (e.g., Arnett, 2004), it does not seem that the type of parental involvement indicative of helicopter parenting is appropriate for the developmental demands of the time period. It would seem that emerging adults should be personally invested in their own growth and development by solving their own problems with roommates, making their own decisions about employment, and seeking their own help from professors. By not doing so, emerging adults may be robbing themselves of the experiences and practice necessary to develop skills that are essential for success in marriage, careers, and adult social interactions.

Most parents of emerging adults agree with the notion that children should be learning to become more independent (e.g., Aquilino, 1996; Nelson et al., 2007), underscoring the notion that most parents tend to become less, not more, involved in the day-to-day problems faced by emerging adults. Therefore, while evidence has shown that both behavioral and psychological control appear to be risk factors in the development of emerging adults (e.g., Luyckx et al., 2007; Nelson \& PadillaWalker,2011; Urry et al., 2011), findings from the current study point to another form of intrusive parental behavior (i.e., helicopter parenting) that may likewise place children at risk. However, given that there are in fact apparently positive aspects of helicopter parenting (i.e., involvement, guidance, disclosure, emotional support), there is much to be learned regarding the complex interactions between helicopter parenting and child outcomes in emerging adulthood. Indeed, the findings raise the need for future work to examine outcomes associated with helicopter parenting in a number of important areas in emerging adulthood including academic outcomes, identity development in specific domains, romantic relationships, development of world views and beliefs, and achievement of criteria deemed necessary for adulthood such as accepting responsibility for the consequences of one's actions, becoming financially independent, developing capacities to care for a family, and independent decision making.

\section{Limitations and future directions}

Despite its contributions, the study is not without limitations. First, the sample consisted of college students, and therefore may not be generalizable to a non-student population. There is still relatively little that is known about individual differences in the "forgotten half" (young people who do not attend college after high school; William T. Grant Foundation Commission on work, Family, and Citizenship, 1988), and even less about their parents. Young people who attend college tend to come from higher socio-economic status (SES) families (Pell Institute, 2004) and research has shown that parenting styles tend to vary as a function of SES (see Hoff, Laursen, \& Tardif, 2002, for a review). Therefore, it is possible that the use of helicopter parenting and its correlates may differ in parents of children who do not attend college. However, the results of the current study provide an important foundation from which future work can be conducted examining parental control and 
intrusiveness within non-college populations. Furthermore, given that two-thirds of young people in the United States enter college the year following high school (National Center for Education Statistics, 2002, Table 20-2), findings from the present study may be relevant for a good portion of young people and their parents in the United States.

Second, the participants lacked ethnic diversity. Theoretical and empirical work has shown the importance of examining how parenting is affected by larger sociocultural contexts and conditions such as poverty, segregation, racism, belief/value systems, and acculturation (e.g., Harrison, Wilson, Pine, Chan, \& Buriel, 1990; Taylor, 2000). This body of work suggests that what may be considered adaptive or maladaptive in one setting may be reversed in another context. Therefore, there is a need to replicate these findings in more ethnically diverse samples.

Next, a notable limitation is the correlational nature of the study, which precludes causal inferences. Whereas we have speculated multiple times in the discussion about possible causal processes, the data prevented us from making conclusive statements. Specifically, we have generally proposed that helicopter parenting may lead to problematic outcomes for children but it may be that child characteristics are influencing parenting. There is a plethora of work with young children showing that child characteristics (e.g., temperament, behavior) may predict parenting behavior (e.g., Rubin et al., 1999; Russell, 1997). For example, Rubin et al. (1999) found that children with an inhibited, fearful temperament tended to elicit more overprotective parenting. It may be that parents who perceive their child to be in distress may, with good intentions, swoop in to relieve and help the child. Likewise, parents of emerging adults who engage in helicopter parenting may be doing so in response to certain perceived weaknesses, needs, limitations, or characteristics of the child, or to direct requests for help from the child. That being said, overall the levels of helicopter parenting were relatively low in the current study, and future research might benefit from examining those parents who use high levels of helicopter parenting versus those who use low levels as an extremes approach might offer a clearer look at the effects of helicopter parenting on the minority of emerging adults whose parents are using it extensively. Taken together, future work is needed to examine the bidirectional processes involved in the relation between child characteristics and parenting.

Finally, future work is needed in examining why parents engage in helicopter parenting. In our introduction, we discussed/ hypothesized the role that warmth and concern for the child's well-being might play in why helicopter parents are so intrusive. While results showed that helicopter parenting was related to aspects of the relationship that might reflect warmth (i.e., affection, emotional support), there were no direct links with warmth. That leads us to speculate regarding the impetus for helicopter parents. It may be that parents are in fact concerned for their children's well-being, but their behavior may also be driven by concern for how their children's behavior will reflect on them. In addition, parents might be responding in an over-involved fashion due to parental separation anxiety (e.g., Bartle-Haring, Brucker, \& Hock, 2002; Kins, Soenens, \& Beyers, 2011) or due to a failure to redefine parental legitimate authority, especially in the personal domain, as their child leaves the home (Nucci \& Weber, 1995; Padilla-Walker, 2008). Hence, future work is needed to better understand the reasons parents give for why they tend to hover over their children at this age.

Overall, this study makes several unique contributions to our understanding of parenting in emerging adulthood. Most notably, it is one of the first studies examining the popular culture notion of helicopter parenting. Specifically, it demonstrates that helicopter parenting can be distinguished from behavioral control and psychological control. Furthermore, it provides initial evidence for this form of intrusive parenting being linked to problematic development in emerging adulthood. Whereas psychological control and behavioral control appear to be destructive to children, helicopter parenting may not be conducive to promoting growth by limiting opportunities for emerging adults to practice and develop important skills needed for becoming self-reliant adults.

\section{Acknowledgements}

The authors express appreciation to the instructors and students at all Project READY data collection sites for their assistance. We also are grateful for the grant support of the Family Studies Center at Brigham Young University, and to our colleagues at Loyola University and McDaniel College.

\section{References}

Aquilino, W. S. (1996). The returning adult child and parental experience at midlife. In C. D. Ryff, \& M. M. Seltzer (Eds.), The parental experience in midlife (pp. 423-458). Chicago: University of Chicago Press.

Aquilino, W. S. (2006). Family relationships and support systems in emerging adulthood. In J. J. Arnett, \& J. L. Tanner (Eds.), Emerging adults in America: Coming of age in the 21st century (pp. 193-217). Washington, DC: American Psychological Association.

Arbuckle, J. L. (2010). Amos 19.0 user's guide. Chicago, IL: SPSS, Amos Development Corporation.

Arnett, J. J. (1998). Risk behavior and family role transitions during the twenties. Journal of Youth and Adolescence, 27, 301-320.

Arnett, J. J. (2000). Emerging adulthood: a theory of development from the late teens through the twenties. American Psychologist, 55, 469-480.

Arnett, J. J. (2004). Emerging adulthood: The winding road from the late teens through the twenties. New York: Oxford University Press.

Aunola, K., Stattin, H., \& Nurmi, J.-E. (2000). Parenting styles and adolescents = achievement strategies. Journal of Adolescence, $23,205-222$.

Balistreri, E., \& Busch-Rossnagel, N. A. (1995). Development and preliminary validation of the ego identity process questionnaire. Journal of Adolescence, 18, $179-192$.

Barber, B. K. (1996). Parental psychological control: revisiting a neglected construct. Child Development, 67, 3296-3319.

Barber, B. K. (2002). Intrusive parenting: How psychological control affects children and adolescents. Washington, D.C.: American Psychological Association.

Barber, B. K., \& Harmon, E. L. (2002). Violating the self: parental psychological control of children and adolescents. In B. K. Barber (Ed.), Psychological control of children and adolescents (pp. 15-52). Washington, D.C.: American Psychological Association.

Barber, B. K., Stolz, H. E., \& Olsen, J. A. (2005). Parental support, psychological control, and behavioral control: assessing relevance across time, culture, and method. Monographs of the Society for Research in Child Development, 70, Serial No. 282. 
Bartle-Haring, S., Brucker, P., \& Hock, E. (2002). The impact of separation anxiety on identity development in late adolescence and early adulthood. Journal of Adolescent Research, 17, 439-450.

Baumrind, D. (1971). Current patterns of parental authority. Developmental Psychology, 4, 1-103.

Baumrind, D., \& Black, A. E. (1967). Socialization practices associated with dimensions of competence in preschool boys and girls. Child Development, 38(2), 291-327.

Bayer, J., Sanson, A., \& Hemphill, S. (2006). Parent influences on early childhood internalizing difficulties. Journal of Applied Developmental Psychology, 27, $542-559$.

Bean, R. A., Barber, B. K., \& Crane, D. R. (2006). Parental support, behavioral control, and psychological control among African American youth: the relationships to academic grades, delinquency, and depression. Journal of Family Issues, 27, 1335-1355.

Bean, R. A., Bush, K. R., McKenry, P. C., \& Wilson, S. M. (2003). The impact of parental support, behavioral control, and psychological control on the academic achievement and selfesteem of African American and European American adolescents. Journal of Adolescent Research, 18, 523-541.

Burgess, K. B., Rubin, K. H., Cheah, C. S. L., \& Nelson, J. L. (2001). Behavioral inhibition, social withdrawal, and parenting. In W. R. Crozier, \& L. E. Alden (Eds.), International handbook of social anxiety: Concepts, research, and interventions relating to the self and shyness (pp. 137-158). Sussex, UK: Wiley.

Carbery, J., \& Buhrmester, D. (1998). Friendship and need fulfillment during three phases of young adulthood. Journal of Social and Personal Relationships, 15, 393-409.

Darling, N., \& Steinberg, L. (1993). Parenting style as contact: an integrative model. Psychological Bulletin, 113, 487-496.

Eccles, J. S., Early, D., Frasier, K., Belansky, E., \& McCarthy, K. (1997). The relation of connection, regulation, and support for autonomy to adolescents' functioning. Journal of Adolescent Research, 12, 263-286.

Fredericks, J. A., Blumenfeld, P. C., \& Paris, A. H. (2005). School engagement. In K. A. Moore, \& L. H. Lippman (Eds.), What do children need to flourish? Conceptualizing and measuring indicators of positive development. New York: Springer Science.

Gabriel, T. (August 22, 2010). Students, welcome to college; parents, go home. The New York Times,

Goldstein, S. E., Davis-Kean, P. E., \& Eccles, J. S. (2005). Parents, peers, and problem behavior: a longitudinal investigation of the impact of relationship perceptions and characteristics on the development of adolescent problem behavior. Developmental Psychology, 41, 401-413.

Grolnick, W. S., Ryan, R. M., \& Deci, E. L. (1991). The inner resources for school performance: motivational mediators of children's perceptions of their parents. Journal of Educational Psychology, 83, 508-517.

Harrison, A. O., Wilson, M. N., Pine, C. J., Chan, S. Q., \& Buriel, R. (1990). Family ecologies of ethnic minority children. Child Development, 61, 347-362.

Hart, C. H., Nelson, D. A., Robinson, C. D., Olsen, S. F., \& McNeilly-Choque, M. K. (1998). Overt and relational aggression in Russian nursery-school-age children: parenting style and marital linkages. Developmental Psychology, 34, 687-697.

Hart, C. H., Newell, L. D., \& Olsen, S. F. (2003). Parenting skills and social-communicative competence in childhood. In J. O. Greene, \& B. R. Burleson (Eds.), Handbook of communication and social interaction skills (pp. 753-797). Mahwah, NJ: Erlbaum.

Hart, C. H., Yang, C., Nelson, D. A., Jin, S., Bazarskaya, N., Nelson, L. J., et al. (1998). Peer contact patterns, parenting practices, and preschoolers' social competence in China, Russia, and the United States. In P. Slee, \& K. Rigby (Eds.), Children's peer relations (pp. 3-30). London: Routledge.

Hastings, P. D., Nuselovici, J. N., Rubin, K. H., \& Cheah, C. S. L. (2010). Shyness, parenting and parent-child relationships. In K. H. Rubin, \& R. J. Coplan (Eds.), The development of shyness and social withdrawal (pp. 107-130). NY: Guilford.

Hock, E., Eberly, M., Bartle-Haring, S., Ellwanger, P., \& Widaman, K. (2001). Separation anxiety in parents of adolescents: theoretical significance and scale development. Child Development, 72, 284-298.

Hoff, E., Laursen, B., \& Tardif, T. (2002). Socioeconomic status and parenting. In M. H. Bornstein (Ed.), Handbook of parenting (2nd ed.). (pp. 231-252) Mahwah, NJ: Erlbaum.

Isley, S., O'Neil, R., \& Parke, R. D. (1996). The relation of parental affect and control behaviors to children's classroom acceptance: a concurrent and predictive analysis. Early Education and Development, 7, 7-23.

Kerr, M., \& Stattin, H. (2000). What parents know, how they know it, and several forms of adolescent adjustment: further support for a reinterpretation of monitoring. Developmental Psychology, 36, 366-380.

Kins, E., Soenens, B., \& Beyers, W. (2011). "Why do they have to grow up so fast?" Parental separation anxiety and emerging adults' pathology of separationindividuation. Journal of Clinical Psychology, 67, 647-664.

Luyckx, K., Soenens, B., Vansteenkiste, M., Goossens, L., \& Berzonsky, M. (2007). Parental psychological control and dimensions of identity formation in emerging adulthood. Journal of Family Psychology, 21, 546-550.

Maccoby, E. E., \& Martin, J. A. (1983). Socialization in the context of the family: parent-child interaction. In P. H. Mussen, \& E. M. Hetherington (Eds.), Handbook of child psychology (4th ed.).. Socialization, personality, and social development, Vol. 4 (pp. 1-101) New York: Wiley.

Marano, H. E. (October 2010). Have college freshmen changed. The New York Times.

McShane, K. E., \& Hastings, P. D. (2009). The new friends vignettes: measuring parental psychological control that confers risk for anxious adjustment in preschoolers. International Journal of Behavioral Development, 33, 481-495.

Morris, A. S., Steinberg, L., Sessa, F. M., Avenevoli, S., Silk, J. S., \& Essex, M. J. (2002). Measuring children's perceptions of psychological control: developmental and conceptual considerations. In B. K. Barber (Ed.), Psychological control of children and adolescents (pp. 125-159). Washington, D.C.: American Psychological Association.

Mounts, N. S. (2004). Contributions of parenting and campus climate to freshmen adjustment in a multiethnic sample. Journal of Adolescent Research, 19, $468-491$.

National Center for Education Statistics. (2002). The condition of education, 2002. Washington, DC: U.S. Department of Education. Available. www.nces.gov.

Neeman, J., \& Harter, S. (1986). Manual for the self-perception profile for college students. Unpublished manuscript, University of Denver, Denver, Colorado.

Nelson, L. J., \& Barry, C. M. (2005). Distinguishing features of emerging adulthood: the role of self-classification as an adult. Journal of Adolescent Research, 20, $242-262$.

Nelson, L. J., Hart, C. H., Wu, B., Yang, C., Roper, S. O., \& Jin, S. (2006). Relations between Chinese mothers' parenting practices and social withdrawal in early childhood. International Journal of Behavioral Development, 30, 261-271.

Nelson, L. J., \& Padilla-Walker, L. M. (2011) Flourishing and floundering: Multiple trajectories of emerging adult college students.

Nelson, L. J., Padilla-Walker, L. M., Carroll, J. S., Madsen, S., Barry, C. M., \& Badger, S. (2007). 'If you want me to treat you like an adult, start acting like one!' Comparing the criteria that emerging adults and their parents have for adulthood. Journal of Family Psychology, 21, 665-674.

Nelson, L. J., Padilla-Walker, L. M., Christensen, K. J., Evans, C. A., \& Carroll, J. S. (2011). Parenting in emerging adulthood: an examination of parenting clusters and correlates. Journal of Youth and Adolescence, 40, 730-743.

Nucci, L. P., \& Weber, E. K. (1995). Social interactions in the home and the development of young children's conceptions of the personal. Child Development, $66,1438-1452$

Olsen, S. F., Yang, C., Hart, C. H., Robinson, C. C., Wu, P., Nelson, D. A., et al. (2002). Mothers' psychological control and preschool children's behavioral outcomes in China, Russia, and the United States. In B. K. Barber (Ed.), Psychological control of children and adolescents (pp. 235-262). Washington, D.C.: American Psychological Association.

Padilla-Walker, L. M. (2008). Domain-appropriateness of maternal discipline as a predictor of adolescents' positive and negative outcomes. Journal of Family Psychology, 22, 456-464.

Pell Institute. (2004). Indicators of opportunity in higher education. Washington, D.C.: Pell Institute.

Pettit, G. S., Clawson, M. A., Dodge, K. A., \& Bates, J. E. (1996). Stability and change in peer-rejected status: the role of child behavior, parenting, and family ecology. Merrill-Palmer Quarterly, 42, 267-294.

Robbins, R. J. (1994). An assessment of perceptions of parental autonomy support and control: Child and parent correlates. Unpublished Doctoral Dissertation, Department of Psychology, University of Rochester, 1994. 
Rubin, K. H., Burgess, K. B., \& Hastings, P. D. (2002). Stability and social-behavioral consequences of toddlers' inhibited temperament and parenting behaviors. Child Development, 73, 483-495.

Rubin, K. H., Cheah, C. S., \& Fox, N. (2001). Emotion regulation, parenting and display of social reticence in preschoolers. Early Education and Development, 12, 97-115.

Rubin, K. H., Hastings, P. D., Stewart, S. L., Henderson, H. A., \& Chen, X. (1997). The consistency and concomitants of inhibition: some of the children, all of the time. Child Development, 68, 467-483.

Rubin, K. H., Nelson, L. J., Hastings, P., \& Asendorpf, J. (1999). The transaction between parents' perceptions of their children's shyness and their parenting styles. International Journal of Behavioral Development, 23, 937-957.

Russell, A. (1997). Individual and family factors contributing to mothers' and fathers' positive parenting. International Journal of Behavioral Development, 21, $111-132$.

Schaefer, E. S. (1965a). Children's reports of parental behavior: an inventory. Child Development, 36, 413-424.

Schaefer, E. S. (1965b). A configurational analysis of children's reports of parent behavior. Journal of Consulting Psychology, 29, 552-557.

Schnaiberg, A., \& Goldenberg, S. (1989). From empty nest to crowded nest: the dynamics of incompletely-launched young adults. Social Problems, 36(3), 251-269.

Soenens, B., Vansteenkiste, M., Duriez, B., \& Goossens, L. (2006). In search of the sources of psychologically controlling parenting: the role of parental separation anxiety and parental maladaptive perfectionism. Journal of Research on Adolescence, 16, 539-559.

Soenens, B., Vansteenkiste, M., \& Luyten, P. (2010). Towards a domain-specific approach to the study of parental psychological control: distinguishing between dependency-oriented and achievement-oriented psychological control. Journal of Personality, 78, 217-256.

Steinberg, L., Lamborn, S. D., Darling, N., Mounts, N. S., \& Dornbusch, S. M. (1994). Over-time changes in adjustment and competence among adolescents from authoritative, authoritarian, indulgent, and neglectful families. Child Development, 65, 754-770.

Taylor, R. L. (2000). Racial, ethnic, and cultural diversities in families. In D. H. Demo, K. R. Allen, \& M. A. Fine (Eds.), Handbook of family diversity (pp. 232251). New York: Oxford University Press.

Thomasgard, M., \& Metz, W. P. (1993). Parental overprotection revisited. Child Psychiatry and Human Development, 24, 67-80.

Urry, S., Nelson, L. J., \& Padilla-Walker, L. M. (2011). Mother knows best: psychological control, child disclosure, and maternal knowledge in emerging adulthood. Journal of Family Studies, 17, 157-173.

William T. Grant Foundation commission on Work, Family, and Citizenship. (1988). The forgotten half: Non-college-bound youth in America. Washington, DC: William T. Grant Foundation. 